\title{
Reliability of the organizational-and- technological model of clusters of sustainable urban residential development
}

\author{
Mikhail Semenenko*, Nikita Guryanov \\ Moscow State University of Civil Engineering, 129377, Moscow, Russia
}

\begin{abstract}
The aim of this study is to determine the interpretation of the term "Cluster of urban residential development" used in the organization of reoriented urban enclaves, taking into account the organizational and technological model of the reliability of formation. In the implementation of such plans, a set of joint tasks of the organizational and technological structure is determined and a number of parameters are taken into account, (comfortable living, with meaningfully used free space; a combination of residential buildings with social, educational, cultural, household and entertainment facilities, etc.), and also - the basic principles of the formation of the reliability of the organizational and technological model of the cluster of urban residential development. The underlying scientific theory is that by using the methods of organizational and technological modeling and system engineering, the indicators of the total durability of construction design can be increased. As a result of the study, the characteristic properties of a cluster of urban residential development were established to be used in an integrated model.
\end{abstract}

\section{Introduction}

Based on world principles, it is important to say that different cities have developed in a chaotic manner. This can still be seen on the master plans of large cities. So, for example, Moscow's development has a circular shape, in which the highways run radially in different directions of the cardinal points from the historical center. Land use planning in combination with the formation of urban space promotes denser development focusing on public transport. The equally important becomes relationship between strategic design and large construction, liquid projects of space formation. In such spatial projects, the main component is the organization of the infrastructure, in which the most priority links are of the type "use of territory - traffic", they must contain a primary role, after that, the tasks of other forms of urban supply should be settled, in particular, the main water supply and sanitation networks. Typically, an urban design scheme lacks the observation and analysis that shape the system's performance. It is recommended that observation scores and indicators be incorporated into the urban design complex as mandatory options, along with indicators, appropriate objectives, plans and unified goal theses. In urban projects, it is

\footnotetext{
${ }^{*}$ Corresponding author: MikhailSemenenko@mail.ru
} 
necessary to clearly and accurately demonstrate the principles, techniques and process of the analysis [1]. It is not easy to assess the results and impact of implementation of large projects, due to the fact that various reasons and cases exist and make influence in cities. Therefore, it is necessary to concentrate on zone, sector projects, since they are smaller in size and better subject to analysis and observation.

\section{Materials and methods.}

For the successful implementation of the urban planning model of cluster planning, it is necessary to resort to technical, material, mental and transit resources that reduce the likelihood of risks when implementing this type of integrated urban planning policy. The guarantee of the reliability of the formation of a cluster of urban residential development and significant socio-economic productivity during the implementation of the project is the main goal in the preparation of the organizational and technological model. From all of the above, you can form the main methods - the achievement and balanced solution of many problems: by analyzing historical details and implementing the principles of intelligent urbanism. Solving these issues will allow you to take control of the main indicators and adjust them at the selected stage of implementation.

\section{Principles of Intelligent Urbanism}

That is a theory of municipal design, which includes a set of ten principles calculated to guide the development of municipal projects and planning. They are designed to align and engage a variety of municipal design and management issues. These principles contain environmental sustainability, heritage conservation, appropriate technology, infrastructureefficiency, placemaking, social access, transit-oriented development, regional integration, human scale, and institutional integrity. The concept was introduced by Professor Christopher Charles Benninger.

\section{Principle one: environmental sustainability}

The principle states that outrageous "anti-environmental impacts" include cutting down trees on hillsides, development of production on the slopes, drainage of sewage and industrial waste water into the natural drainage system, excessive pavement and slab construction, as well as designing on steep slopes. This urban theory plans that ecological equilibrium in cities can be maintained when shaky areas are saved, ecosystems are preserved, and low-density areas are scrupulously established. Likewise, the norms function within the boundaries of natural balance with the task of protecting and maintaining those components of ecology that saturate the environment. Therefore, the first principle of urban development explains that urbanization should remain in balance with nature.

\section{Principle two: heritage conservation}

This principle is based on care for the unique cultural and social iconography of the regions, their signs and indicators. Their input into the areal regulations of city requirements is supported. Proponents promote the targeting and structuring of urban projects by applying local skills and conceptual frameworks embodied through creativity, urban area and architecture. Design definitions must be carried out within the heritage equilibrium, while hostilely defending, encouraging and maintaining the unified elements and constituents of the urban template.

Principle three: appropriate technology

Appropriate technology emphasizes the application of construction materials, technologies, urban schemes and management programs that meet local requirements. Human potentials, climatic conditions, local sourcing and corresponding fundamental 
investments all hold the technology back. Where there are abundant craftspeople, laborintensive methods are appropriate. Where there is surplus savings, capital intensive methods are appropriate. This principle is in sync with "small is beautiful" concepts and with the use of local resources.

Principle four: conviviality

The fourth principle sponsors social interaction through public domains, in a hierarchy of places, devised for personal solace, companionship, romance, domesticity, "neighborliness," community and civic life. The principle maintain that this can be achieved through design and that society operates within hierarchies of social relations which are space specific. The hierarchies can be conceptualized as a system of social tiers, with each tier having a corresponding physical place in the settlement structure.

Principle five: efficiency

The principle of efficiency promotes a balance between the consumption of resources such as energy, time and fiscal resources, with planned achievements in comfort, safety, security, access, tenure, productivity and hygiene. It encourages optimum sharing of public land, roads, facilities, services and infrastructural networks, reducing per household costs, while increasing affordability, productivity, access and civic viability.

Principle six: human scale

The principle encourages ground level, pedestrian oriented urban patterns, based on the analysis of society. Walkable, mixed use urban villages are encouraged over singlefunction blocks, linked by motor ways, and surrounded by parking lots.

Principle seven: opportunity matrix

The PIU envisions the city as a vehicle of opportunities. But they are divided unequally. The principle promotes a guaranteed access to education, health care, police protection, and justice before the law, potable water, and a range of basic services.

Principle eight: regional integration

The principle envisions the city as an organic part of a larger environmental, socioeconomic and cultural-geographic system, essential for its sustainability. This zone of influence is the region. Likewise, it sees the region as integrally connected to the city. The principle sees the planning of the city and its hinterland as a single holistic process.

Principle nine: balanced movement

The principle advocates integrated transport systems comprising walkways, cycle paths, bus lanes, dedicated under-ground light rail corridors, automobile and metro channels. A balance between appropriate modes of movement is proposed.

Principle ten: institutional transparency

The principleholds that good practices inherent in considered principles can only be realized through accountable, transparent, competent and participatory local governance, founded on appropriate data bases, due entitlements, civic responsibilities and duties. Intelligent urbanism envisions the institutional framework as being very clear about the rules and regulations it sponsors and that those using discretion in implementing these measures must do so in a totally open, recorded and transparent manner [2].

The concept of cluster development (i.e., district, micro-district and quarter) appeared at the beginning of the 20th century. The structure of urban development has the following character: the city is divided into districts, the districts, in turn, have micro-districts, which are also divided into quarters.

Regional divisions in megalopolises and cities have always been based on the number of people living, that is, on the population density. So, when organizing construction, it is assumed that a particular plan of quarterly development is designed for a certain number of people. Thus, subsequent analytics are produced, which is the calculation of the necessary infrastructure and the subsequent load (i.e. the required number of kindergartens, schools, sports facilities, hospitals, shops, transport routes, etc.) 
New construction is trying to comply with this plan, but in the already established districts (in the Central Administrative District of Moscow or in the "sleeping" outskirts), active development leads, unfortunately, to the fact that the "fresh" micro-districts in terms of the size of buildings and structures or the number of inhabitants surpass the existing districts and even new districts. In terms of population, sleeping areas and neighborhoods can be compared with the average-sized city in Russia. For example, the highest population density in Moscow is in the Zyablikovo district - here (with an area of 4.4 sq. km) live almost 134 thousand people, which is comparable to the population of the town of Odintsovo near Moscow.

Where did one of the types of typical building - micro-district come from?The idea to provide residents of states with digestible multi-storey housing appeared in the $30 \mathrm{~s}$ of the XX century in European countries. In the USSR, during the years of collectivization, the process of urban development moved at a tremendous pace. The general industrialization of the Soviet Union led to the need for the construction of a high rate of inexpensive housing for workers. The population of the cities was growing and many could not be provided with a "roof over their heads". Despite the catastrophic shortage of housing, the country's leadership was engaged in the construction of facilities other than the development of projects for multiapartment residential buildings. One of the most important priorities was to eliminate the problem of providing the people with housing, which became even more acute after the Great Patriotic War, i.e. 45s - early 50s.Khrushchev N.S. in 1956 set the task to solve the "apartment" problem.Work on the design of housing, which could correspond to the economic realities of the time, was carried out tirelessly. [3].

Interest has increased, the need did not subside. Structures progressed in size as engineering progressed. By the end of the 60 s the standard residential building was 11storey [4].

The construction industry sought to reduce construction costs, risks, project implementation time and to improve the quality of work [5]. Systematization, automation and improvement of individual processes of technology and organization of construction in the implementation of projects took place systematically.

In addition to all this, it was proposed to determine the housing stock in 4 stages:a large urban area, which includes many micro-districts containing groups of quarters with the main residential groups. Any level was a specific set of functional norms content. Analysts have encouraged the unification of principles in such a way, that the idea of the cluster exhaustively reveals the needs of the social order and municipal society, the idea of the quarter, in contrast, was a model of private life, limited public, locally restrained [6]. From which it follows that by combining the two ideas, the creators discovered a universal urbanistic measure - a micro-district delimited by its natural habitat into numerous zones quarters. The norms held by the discussions about the unified concept were as follows: location of the residential area and service structures on the combined area, including the location of local labor and safe industry; lack of temporary traffic on the area of the microdistrict; socially important elements must be placed within walking distance; the specific saturation of housing must satisfy the number of people; availability of a spatial web of green locations.

K.V. Kiyanenko believed that the modern development of residential designed modules gave rise to criticism of residents for the shortcomings of public stay, for the inability to reflect all the difficulty of social, production and technological problems, forming low sanitary and hygienic requirements, traffic difficulties, huge waste of time, fragmentation of the population with an amazingly gloomy construction [7]. The device of the government "conveyor" for the formation of the housing stock was completely separated from further residents, taking away from them any prospect of being involved in the settlement and construction process or influencing its outcomes, transforming people into submissive, 
inactive "buyers". The creator focuses on the fact that the residential area did not correspond to the diversity of people, their needs, lifestyles, standards of enlightenment, and forced to adapt to this disagreement at a high price with significant social and mental costs [8].

The object of discussion of the foundations of the design of house developed units was considered: the severity of the working zoning of the plan of residential design measures, the level arrangement for servicing residential areas;redundancy of unfilled spaces; lack of regulation of relief-ecological obstacles of the housing stock [9]; contradiction of industrial technologies of serial construction of the public application of society; hostility of residential construction, with leading uniformity and facelessness; in the general picture, everything did not contribute to the formation of social relationships in the residential environment [10].

Quarter districts are built using the doctrine of mixed development, when all objects and centers required by a person are located within walking distance. This reduces the pendulum migration within the urban space, reduces the load on the road infrastructure [11], the public transport network, and develops pedestrian and bicycle infrastructure in a given area. As a result, there is a social demand for the necessary formation of urban planning policy.

Proper distribution of two-three-stored buildings, erected close;five to eight-storey complexes with an underground level of parking and a successful location of state, social and religious institutions will allow to form the most fruitful environment for a comfortable life of a person [12].

\section{Results and discussions.}

New projects were evaluated on the basis of cost efficiency and overall rationality, which was synonymous with cheapness and simplicity, and how the program justifies the expenses.

In 1959, Soviet Russia created its first DSK - the Integrated House-Building Plant, whose task was to produce prefabricated panels for house planning on a mass scale. From the beginning of the 50s, the proper plans were developed and adjusted in the Architectural and Planning Department. These were panel houses, as a rule, with a number of stores equal to 5, which, in turn, had the opportunity to have the required length, thanks to sectional development and subsequent unification. In the future, another 400 such organizations as DSK appeared.

Nikita Sergeevich's reforms led to a departure from small-sized cities, in which their central part held a historical attraction. New construction took place on the urban periphery. With rare exceptions, construction was carried out in the existing areas. However, the obligatory norm was the construction of residential areas along with the municipal infrastructure (grocery stores, educational institutions, clinics, sports grounds and preschool institutions) - the very same micro-district appeared.

The micro-district construction zones of the 50s are connected by Cheryomushki in the South-West Administrative District of Moscow, Khoroshevo-Mnevniki in the North-West Administrative District and Kuzminki in the South-Eastern Administrative District. The first such large residential area for people was the test quarter "Cheryomushki" with its buildings designed for 3 thousand inhabitants, grocery stores, preschool and school institutions, a cinema hall. Citizens received here separate 2 or 3 -room apartments with everything necessary (bathrooms with bathtubs, separate kitchen areas, bedrooms) and equipped according to the appropriate requirements of the Soviet people.

Since then, housing of new standards with the conveniences corresponding to the times has been considered as an achievement of the advanced Soviet way of life and a new 
condition for the formation of a citizen who keeps up with the times, a person of the era of the international community. Prefabricated panel houses had the image of urban and social reformation approaches to construction. All sets of apartment buildings, gymnasiums, preschool institutions, sports grounds were understood as the dream of every Soviet citizen. The micro-districts were supposed to create a living environment in which a collective system could be created. Architects and city planners understood that the residents of the districts themselves played a big role, paying attention to "educational and ideological activities among citizens, friendly mutual assistance, caring for trees and shrubs, preserving the integrity of the home and adjoining territories, independent small maintenance."

Typical micro-districts appeared throughout the USSR and imperceptibly received the status of the most recognizable and popular types of development. By the $80 \mathrm{~s}$ of the twentieth century, $68 \%$ of residential housing in Moscow was typical. By this period, such houses had the opportunity to be seen throughout the USSR from the Baltics to the Far East.

\section{Comfortable city: CONSTRUCTION DENSITY FOR EVERYDAY LIFE}

This building density can be built with very different buildings and different spaces between them. The fourth example has the same density. Each of them has a total area of 22,400 $\mathrm{m} 2$.Notable aspects are the closedness or safety of a given space and this can be more useful than an open space.The length of the building can create a favorable street area, and part of the first and upper floors (or penthouse) can be more useful and attractive, and often have economic value.

Fig. 1. Cluster development scheme - Tower

Inexpensive apartments of the Khrushchev era were originally built for a standard family in the amount of $3-4$ people, but often families lived in larger numbers. In the future, they were replaced by new types of residential areas, already of a more decent quality, but in principle, the construction method and urban planning policy did not change. The courtyard area consisted of entrances to houses, a number of parking spaces, a playground between and planted trees and shrubs. Several decades have passed, and only one thing has changed - the increase in the number of parking spaces in the yards.

At the end of the twentieth century. In the urban planning policy of the USSR, studies of the rational use of lands are becoming important. Urban planners stated that the essence of space features demonstrates the optimal dependence of the use of zones in the urban sphere. For the functional planning factors of the design of micro-districts, the thesis of building density appears. The leading influence on building density is the creation of private and general details of the urban planning configuration, which includes a multi-level residential area, systematization of infrastructural and public services, qualitative assessment of landscaping, technical equipment, assessment of labor (time) costs on the way of movement, the level of convenience of urban space.

We also analyzed the relationship of the underlying causes, situations and initial conditions that determine the density of micro-district construction: climatic, social, sanitary and hygienic, economic, architectural and expressive, including the assessment of the construction and design configuration of houses, the procedure for the construction of a residential area, etc. 
In the development of the analysis, the basic features of the active exploitation of builtup units have been formed - the introduced term "The saturation of house units, a multiple of the unit of the territory of the entire area of the housing stock - the force with the outer shell, to the unit of living space in the housing stock of the district - the force without the outer shell." The concept of "territorial increase in the productivity of the housing stock" appears - increase in the density of micro-district territorial development. Based on the results of tender planning, academic and research-applied analysis, an interpretation of the micro-district was developed, as an element of systemic planning and integrated construction, providing for the rationality of activities - many everyday needs in education, health services, sports provision, road traffic regulation.

\section{Organizational and technological reliability}

The use of cluster technology of the organization will ensure an increase in the efficiency of management of the social sphere of the region due to a more rational distribution of all types of resources, growth in the number of social infrastructure organizations in the region, rapid spread of innovations in their work, increasing the level of satisfaction of the population with the quality of healthcare services, housing and communal services, education, culture and leisure.

The main goal of the organizational and production model is high economic and social efficiency of the implementation and functioning of the cluster urban housing development. The consequence and logical continuation of the main goal is the achievement of many private goals: economic, social, technical and technological, environmental, allowing detailed control of parameters and promptly adjusting them at all stages of the project. Ranking goals and objectives in order of importance allows you to quickly make adjustments to the project and manage risks at all stages from concept to commissioning of the facility. At the same time, modeling and algorithmicizing of this process makes it possible to form a systematic approach to solving urban planning issues, taking into account optimal organizational and technological solutions, ensuring the timely commissioning of safe and reliable buildings as part of a cluster of urban residential development.

The micro-district turns into a key primary self-sufficient object of the city design structure,the area, the saturation and number of the electorate of which was characterized by the formation of a reasonable scheme of centers, providing services and their infrastructural acceptability; the saturation of housing development was characterized by the determined height, length of structures and climatic environments.

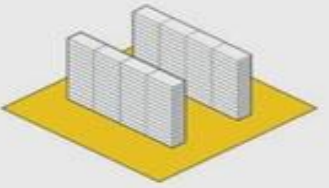

Parallel development

14 floors

Building area: $1600 \mathrm{~m} 2$

$7 \%$ ground floor

$7 \%$ penthouse

Lift height $29 \%$

Street length: $360 \mathrm{~m}$

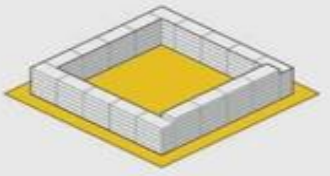

Large courtyard 6-7 floors

Building area: $3600 \mathrm{~m} 2$

$16 \%$ ground floor

$16 \%$ top floor /

"penthouse"

Lift height $67 \%$

Street length: $400 \mathrm{~m}$ 
Fig. 2. Cluster development scheme - Parallel and Big courtyard

According to the decrees and regulations for the development and direct construction in the residential area, it is necessary to form topical residential groups, public and adjacent open "green" spaces.

In the papers of 70-80th years subjects of conversation about "social-spatial division", "social and property division", "competitiveness of social needs", "competition for limited urban planning funds", etc. make their way into the science of urbanism. Experts, discussing the ruthlessness of the concept of "life-work-rest", paid attention to: «In fact, the city is a whole material-volumetric condition, where complex sectoral, educational and everyday operations are carried out, during which citizens belonging to various social and ethnographic strata enter into multiple connections, enter into the existence of diverse associations and communities, not being limited to one zone of the enclave or role-playing part of the city".

At the end of the $60 \mathrm{~s}$, in the Western states there was a surge of social rejection of the approved sectoral methods of creating an urban area. So, a residential area in St. Louis, built in accordance with all the best methods of modeling systems, awarded by the Institute of Architecture of the United States, was brutally mutilated by residents, and subsequently blown up by the decision of the municipality in 1972. Also, in the American city of Chicago, a phased reconstruction of the Park Boulevard micro-district was carried out. Local residential properties were destroyed and low-rise buildings were erected with social projects on the first levels. Analysts drew attention to the fact that the sudden response of society to the construction of "modern" clusters was generated by the inaccessibility of actual public mandate.

Design and urban planning policy was defined as a model of a bureaucratic, "top-down" and verifiable procedure for the formation of the surrounding layer, where engineers rarely met a social figure as a "material subject". In the $80 \mathrm{~s}$, public research was extensively introduced in foreign countries, revealing the relationship between residents and the environment of permanent residence, due to a chain of social disagreements.

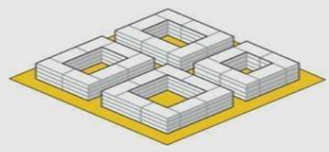

Small courtyard

4 floors

Building area: $5600 \mathrm{~m} 2$

$25 \%$ ground floor

$25 \%$ top floor / penthouse

Lift height $100 \%$

Street length: $720 \mathrm{~m}$
Building walls help to provide

that noise from streets and public places, especially

from traffic movement, excluded.Silence and peace are highly valued in a densely populated city, and the fence can even allow you to sleep with an open window to the courtyard.

The built-in case can also block air pollutants, which means cleaner air for ventilation, and the wash can be hung out to dry.Although the urban structure of a closed quarter precedes the appearance of motorized vehicles, it is practical for work withthem.

Vehicle access to buildings is required for emergency services, delivery and pick-up or drop-off at the door.However, motorized vehicles bring noise, smoke and potential danger with them.

Fig.3. Cluster development scheme - Quarterly

Quarter development is one of the methods for solving the difficulties of the housing stock of clusters. In order to see methods for solving similar difficulties, it is prudent to revise the studies of Western urban planners. The construction of suburbs in the United States is also not a benchmark. In the UK, urban planners have approached this issue in principle. The capital of England, relative to Russian cities, was erected not according to 
the micro-district approach, but according to the quarterly approach. The area is divided into a small number of quarters. The quarters, in turn, have streets with a modest carriageway and very spacious pedestrian zones inside them. The dwellings have a small or medium number of levels, are densely built up among themselves and have plots in front of them. As a rule, grocery stores, restaurants and other elements of small business are located on the first levels; some houses include underground parking. The space inside the building is used both for everyday tasks and as a place of rest and leisure for residents of the area.

The advantages of this development are as follows:

1. The quarterly type of residential development does not cause mental discomfort among citizens. Thanks to the dynamic exteriors, the environment that runs along the street, the absence of large unused spaces and the commensurability of man and buildings, a comfortable environment is formed.

2. This type of development is safer due to the use of the established limit for car movement and the formation of requirements for the continuous activity of residents in the presented area.

3. When erecting in a quarterly layout, they try to bypass the forced typification of buildings and social clusters, which makes the resulting environment more outstanding.

4. The degree of properties of the attributes of life in the residential area is increasing. It is worth emphasizing that unified neighborhoods, unfortunately, become disadvantaged clusters over time. This problem is not observed in quarterly type of development. Their construction must be carried out with buildings of different levels of stores depending of the functional conditionality of the territory.

\author{
The external environment of the \\ cluster functioning \\ -Elements of financial and credit \\ infrastructure \\ -Regional government bodies
}

\author{
Internal environment of cluster functioning \\ - personnel suppliers \\ Organizationsof basic vocational training, secondary \\ vocational training, higher vocational training \\ Resource centers \\ Training centers \\ Construction companies \\ building and construction \\ scientific, design and survey organizations \\ -Elements of infrastructure \\ informational \\ Logistic-household \\ investment \\ innovative \\ - Providers of Goods and Services
}

Fig. 4. Block diagram of the cluster functioning.

\section{Conclusions}

1. At the start of the XXI century, modern types of residential planning units were established due to their typological, socially developed, functional design, naturalecological and administrative-managerial updates.

2. On the basis of combining the concepts of house designed units, new types have appeared: "residential area", "quarter", "commune"; as a result of the distribution of the cluster of functions from the outskirts to the center, a centripetal type of residential compositional part was formed - "Transport-oriented"; as a result of the formation of 
practical approaches of the worldview, focused on the person - "association of associations".

3. By the end of the XX - beginning of the XXI centuries. the main directions of the formation of projected housing units were formed: the complication of the typological composition; revision of the essence and content of public places; the formation of design units as a public administration and economic component of the city.

4. In the method of urban planning of the environment, a relief-natural ideology was formed in the study, planning and restoration of residential project objects, as well as methods of custom planning.

5. The spatial organization of residential design objects is wielded with fixed and variable components.

6. The main laws of the formation of residential design objects at the beginning of the XXI century should be considered: physical, social and economic accessibility; volumetric, socio-economic and conditional mobility; adherence to separation and role spaces; recognition of the physical-object and social enlightenment atmosphere of the habitat;cooperation of qualified, public secular communities; relief-natural ideology; adaptability of the adopted developed solutions; public information planning strategy.

\section{References}

1. A.V. Voronin, Regional economy: theory and practice (2007)

2. D.V. Topchiy, Technology and organization of construction production 4-1, 34-41 (2015)

3. V. Holodkova, A.Mottaeva, T. Pokrovskaya, E3S Web of Conferences 164, 11043 (2020) https://doi.org/10.1051/e3sconf/202016411043

4. K.V. Kiyanenko, Architecture and Social Modeling of Homes (2005)

5. A.P. Obedkov, Questions of service and economics 6 (2014)

6. A.E. Balakina et al., Study of the peculiarities of the formation of a residential neighborhood in the course design of multi-apartment residential building (Moscow, 2012)

7. E.G. Animitsa, Strategic planning of territorial development: essence, basic principles, problems (2018)

8. A. Zheltenkov et. al., IOP Conference Series: Earth and Environmental Science 90(1), 012122(2017)

9. Graz Biennale, "Imagination and Urban Design", K. Benninger, in the materials of the Graz Biennale, Graz (2001) 